\title{
SELECTION OF HEAT TREATMENT PARAMETERS FOR A CAST ALLVAC 718Plus® ALLOY
}

\author{
Oscar Caballero $^{1}$, Kepa Celaya ${ }^{1}$, Tomás Gomez-Acebo ${ }^{2}$, Antonio Julio Lopez ${ }^{2}$ \\ ${ }^{1}$ ITP, Industria de Turbo Propulsores, S.A. \\ Edificio no. 300, Parque Tecnológico, 48170 Zamudio, Vizcaya, Spain \\ ${ }^{2}$ CEIT Centro de Estudios e Investigaciones Técnicas \\ Paseo Manuel Lardizabal, 15, 20009 San Sebastián, Guipuzcoa, Spain
}

Keywords: 718Plus, casting, heat treatment, VITAL R\&D

\begin{abstract}
The first selection of best set of parameters for heat treating a cast Allvac 718Plus alloy is presented in this paper. The high interest from several aeroengine manufacturers in this new alloy with improved temperature capabilities over widely used In718 has driven the development of the alloy also in the direction of making available a cast form of it. A first step in this direction was to use some available material (billet originally intended to be used for forging other parts) as remelting stock for producing a couple of cast rings and use them as test material for assessment of different sets of heat treatment parameters. In particular, the application of homogenization before HIP and the solution temperature after HIP are discussed. Use of hardness measurements and optical microscopy were made to help in the assessment of the effect of the homogenization cycle, and also the effect of the different solution temperatures. Other techniques such as Scanning Electron Microscope and X-Ray Diffraction were tried for identification and quantification of hardening phases.
\end{abstract}

\section{Introduction}

Alloy Allvac 718Plus has been marketed by its inventor, Dr W.D. Cao, and producer company, Allvac, and several articles have been published or fostered from the company to show the advantages over the widely used In $718[1,2,3]$. The new alloy claims to offer better mechanical properties at those temperatures where In 718 has already exhausted its applicability, in the $650^{\circ} \mathrm{C}$ range. Allvac 718Plus shows improved metallurgical stability at even higher temperatures, up to $700^{\circ} \mathrm{C}$. In this upper range, no degradation of mechanical properties has been noticed for the new alloy [4].

The alloy was originally developed to be used in its wrought form, but requests from aeroengine companies have driven Allvac to perform activities in order to tune-up the chemical composition of the alloy in its cast form and also trim the heat treatment of this application. This paper shows one of the first efforts to select the heat treatment to be applied to this kind of material.

ITP and CEIT were partners in the European VITAL R\&D program, together with Volvo Aero Corporation, where several activities were performed to evaluate the new alloy. One of these was the production of castings in different geometries, such as separately cast test bars, stair shaped plates, hollow rings and a demonstration casting to finally assess castability [5]. The present study consisted of heat treatment trials and mechanical property assessments of cast rings. This paper covers the heat treatment studies. 


\section{Experimental Procedure}

Several cast Allvac 718Plus solid rings were produced at PCB, Baracaldo, Spain, by the conventional investment casting. Dimensions of the rings were $285 \mathrm{~mm}$ OD, $225 \mathrm{~mm}$ ID, and $120 \mathrm{~mm}$ high. See Figure 1.

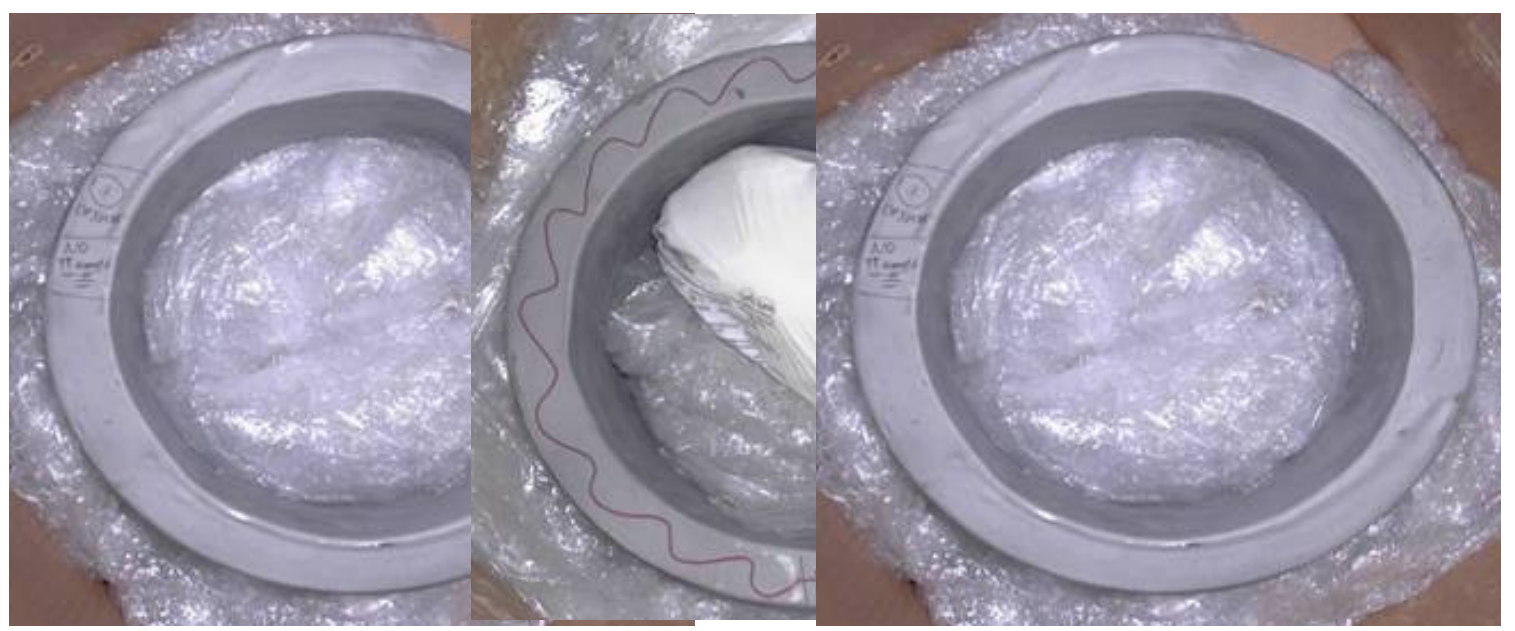

Figure 1. Cast Allvac 718Plus rings produced at PCB.

The remelt stock used for production of these rings was originally intended to be used as forging stock. The chemical composition of the material was that of the billet produced for the VITAL project, used as remelting stock, given in Table 1:

\begin{tabular}{|c|c|c|c|c|c|c|c|c|c|c|c|c|c|c|c|}
\hline $\mathrm{C}$ & $\mathrm{Mn}$ & $\mathrm{Si}$ & $\mathrm{Cr}$ & $\mathrm{Mo}$ & $\mathrm{Co}$ & $\mathrm{Ti}$ & $\mathrm{Al}$ & $\mathrm{B}$ & $\mathrm{Zr}$ & $\mathrm{Fe}$ & $\mathrm{P}$ & $\mathrm{Nb}$ & $\mathrm{W}$ & $\mathrm{V}$ & Nickel \\
\hline 0.19 & 0.04 & 0.04 & 17.8 & 2.67 & 9.0 & 0.75 & 1.43 & 0.004 & $<0.01$ & 9.5 & 0.01 & 5.5 & 1.0 & 0.02 & Bal. \\
\hline
\end{tabular}

Table 1: Chemical composition of 718Plus alloy for production of cast rings, weight percent.

After completing their initial NDT evaluation, several heat treatments were applied to different samples from the rings, as described in Table 2 to study the use of homogenization prior to HIP, and solution temperatures from $954^{\circ} \mathrm{C}$ to $1066^{\circ} \mathrm{C}$ after HIP.

Details of the first steps of heat treatment sequence were as follow:

Ring 1 was homogenized at $1095^{\circ} \mathrm{C}$ for 1 hour, and cooled at 2 bar of Ar pressure.

Both rings were $\mathrm{HIPed}$ at $1120^{\circ} \mathrm{C}$, in $\mathrm{Ar}$ gas at $103 \mathrm{MPa}$ for 4 hours.

The rings were then cut and the different samples underwent solution heat treatments at different temperatures, as described in Table 2. After these solution heat treatments, samples were aged at the usual Allvac 718 Plus parameters: $788^{\circ} \mathrm{C}$ during 8 hours, cool to $704^{\circ} \mathrm{C}$, hold during 8 hours, cool to room temperature.

Finally, the samples received a simulated service treatment of $700^{\circ} \mathrm{C}$ for 140 hours followed by $675^{\circ} \mathrm{C}$ for 460 hours. This simulated cycle represents the most severe conditions that the Allvac cast 718Plus components might be expected to see. These conditions would preclude the use of In718 due to thermal degradation of the material. Only the upper temperature range service conditions were simulated. Table 2 shows the whole set of produced samples. HHX is the 
reference for Homogenised and HIPed sample number X, and NHY is the reference for the only HIPed sample numberY.

\begin{tabular}{|c|c|c|c|c|}
\hline $\begin{array}{c}\text { Solution } \\
\text { Temperature }\end{array}$ & As produced (after HIP) & Solutioned & Aged & Exposed \\
\hline Without solution & HH0/NH0 & Not applied & Not applied & Not applied \\
\hline $954^{\circ} \mathrm{C}$ & N/A & HH1/NH1 & HH6/NH6 & HH11/NH11 \\
\hline $982^{\circ} \mathrm{C}$ & N/A & HH2/NH2 & HH7/NH7 & HH12/NH12 \\
\hline $1010^{\circ} \mathrm{C}$ & N/A & HH3/NH3 & HH8/NH8 & HH13/NH13 \\
\hline $1038^{\circ} \mathrm{C}$ & N/A & HH4/NH4 & HH9/NH9 & HH14/NH14 \\
\hline $1066^{\circ} \mathrm{C}$ & N/A & HH5/NH5 & HH10/NH10 & HH15/NH15 \\
\hline
\end{tabular}

Table 2: Set of samples investigated, with different solution heat treatment temperatures and addition of HIP.

Hardness testing and microstructural observations were used to assess the results of the different applied heat treatments. Rockwell $\mathrm{C}$ and Vickers measurements were used initially to assess macroscopic and microscopic features of the heat treated material. As the scatter of the obtained values was outside the valid range in some of the samples, it was afterwards decided to use the Brinell scale to allow for comparisons amongst all the different samples.

\section{Results}

The values obtained from the Brinell hardness measurements are shown in Table 3. Each value is an average of measurements taken af five different points.

\begin{tabular}{|c|c|c|c|c|}
\hline & \multicolumn{4}{|c|}{ Brinell Hardness, HB } \\
\hline $\begin{array}{l}\text { Heat Treat } \\
\text { Parameters }\end{array}$ & As produced (after HIP) & Solutioned & Aged & Exposed \\
\hline Hom, HIP & HH0 302 & & & \\
\hline Hom, HIP, $954^{\circ} \mathrm{C}$ & \multirow{5}{*}{$\begin{array}{l}\text { N/A } \\
\text { N/A } \\
\text { N/A } \\
\text { N/A } \\
\text { N/A } \\
\end{array}$} & HH1 251 & HH6 379 & $\begin{array}{ll}\text { HH11 } 367\end{array}$ \\
\hline Hom, HIP, $982^{\circ} \mathrm{C}$ & & HH2 256 & HH7 356 & HH12 364 \\
\hline Hom, HIP, $1010^{\circ} \mathrm{C}$ & & HH3 226 & HH8 364 & HH13 373 \\
\hline Hom, HIP, $1038^{\circ} \mathrm{C}$ & & HH4 217 & HH9 351 & HH14 389 \\
\hline Hom, HIP, $1066^{\circ} \mathrm{C}$ & & HH5 218 & HH10 371 & HH15 413 \\
\hline HIP & NH0 310 & & & \\
\hline $\mathrm{HIP}, 954^{\circ} \mathrm{C}$ & \multirow{5}{*}{$\begin{array}{l}\text { N/A } \\
\text { N/A } \\
\text { N/A } \\
\text { N/A } \\
\text { N/A }\end{array}$} & NH1 257 & NH6 365 & NH11 362 \\
\hline $\mathrm{HIP}, 982^{\circ} \mathrm{C}$ & & NH2 261 & NH7 358 & NH12 369 \\
\hline $\mathrm{HIP}, 1010^{\circ} \mathrm{C}$ & & NH3 213 & NH8 353 & NH13 377 \\
\hline $\mathrm{HIP}, 1038^{\circ} \mathrm{C}$ & & NH4 227 & NH9 363 & NH14 373 \\
\hline $\mathrm{HIP}, 1066^{\circ} \mathrm{C}$ & & NH5 221 & NH10 373 & NH15 383 \\
\hline
\end{tabular}

Table 3: Brinell hardness values of the samples obtained after heat treatment trials.

The values are plotted in Figures 2 and 3. 


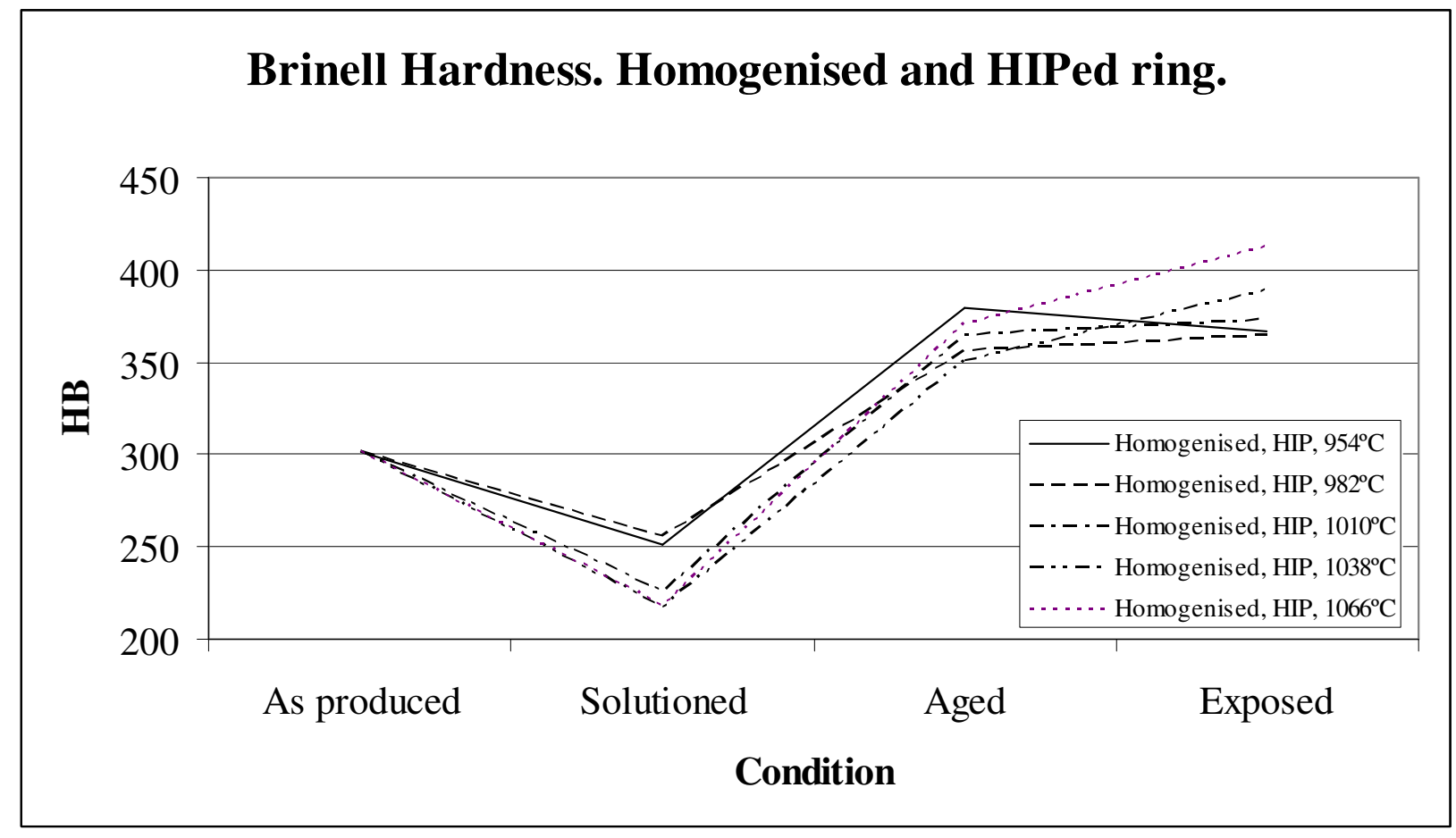

Figure 2: Average values of Brinell hardness on metallographic examples from Homogenized and HIPed ring with different solution temperatures.

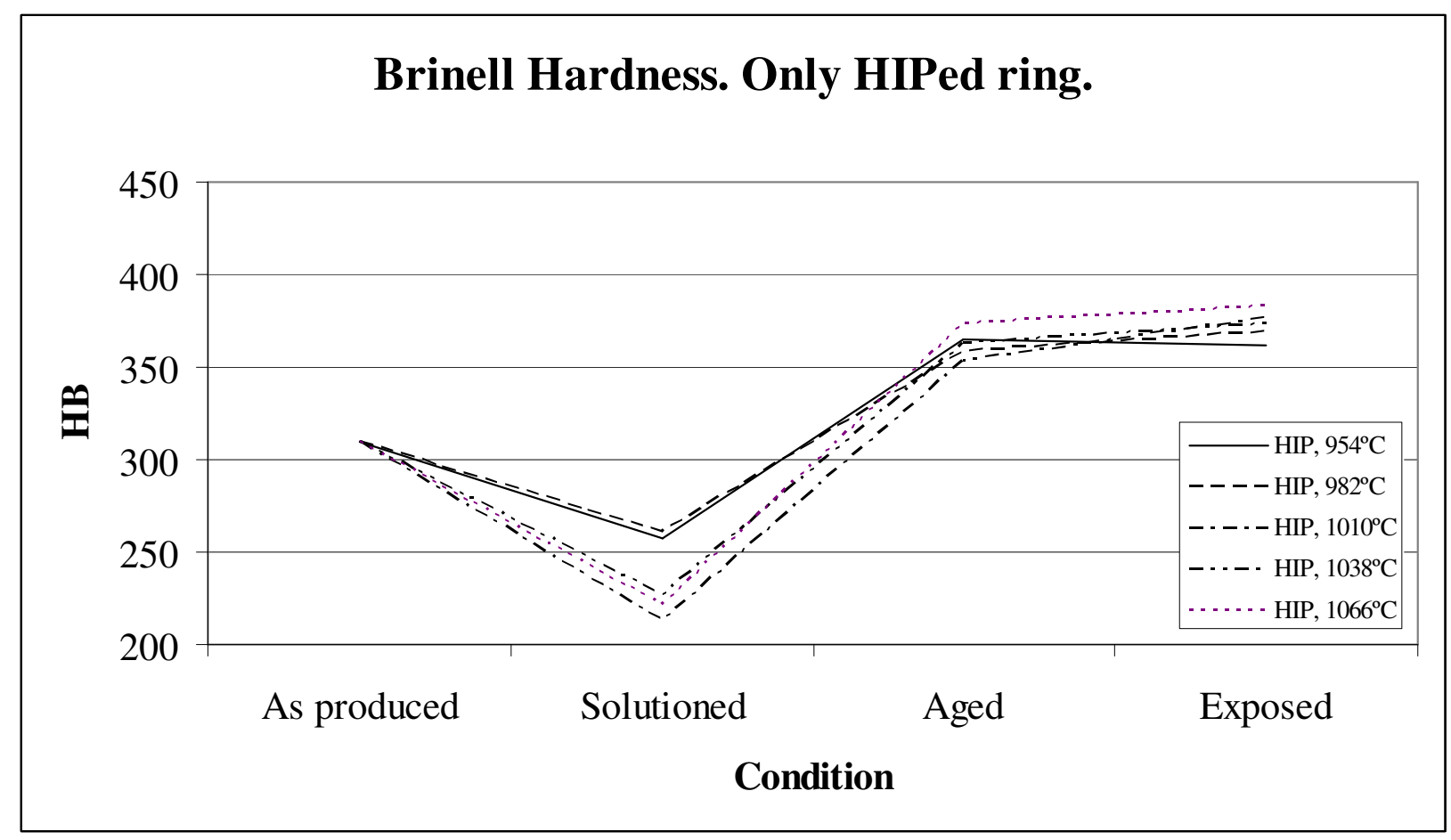

Figure 3: Average values of Brinell hardness on metallographic examples from only HIPed ring with different solution temperatures.

Comparison between both sets of data shows that the hardness values of the homogenized samples increased after the simulated service exposure conditions, especially the samples that 
were heat treated at higher solution temperatures. This is attributed to a larger amount of available $\mathrm{Nb}$ and other hardening elements in the matrix for forming precipitates, as the homogenization cycle has contributed to dissolve the segregations and place those elements into solution in the matrix. The homogenization heat treatment worked out satisfactorily in spite of being $1 \mathrm{hr}$ and $1095^{\circ} \mathrm{C}$, that is shorter and at lower temperature that the HIP. In fact, measurements on samples revealed that $\mathrm{Nb}$ segregations percentages were always reduced by the homogenization cycle. Comparing Micrographs 1 versus 2, solutioned at one temperature, and Micrographs 3 versus 4, solutioned at another different temperature, the size and percentage of $\mathrm{Nb}$ segregations are larger in the only HIPed metallographic samples. On the homogenized metallographic samples, the phases are more evenly distributed. Measurements of volumetric fractions of $\mathrm{Nb}$ segregations were perfomed on micrographs of etched material that were analysed through Leica Qwin image analysis program. This effect of higher dissolution of the segregations (lower volumetric fraction) was confirmed, see Figure 4.

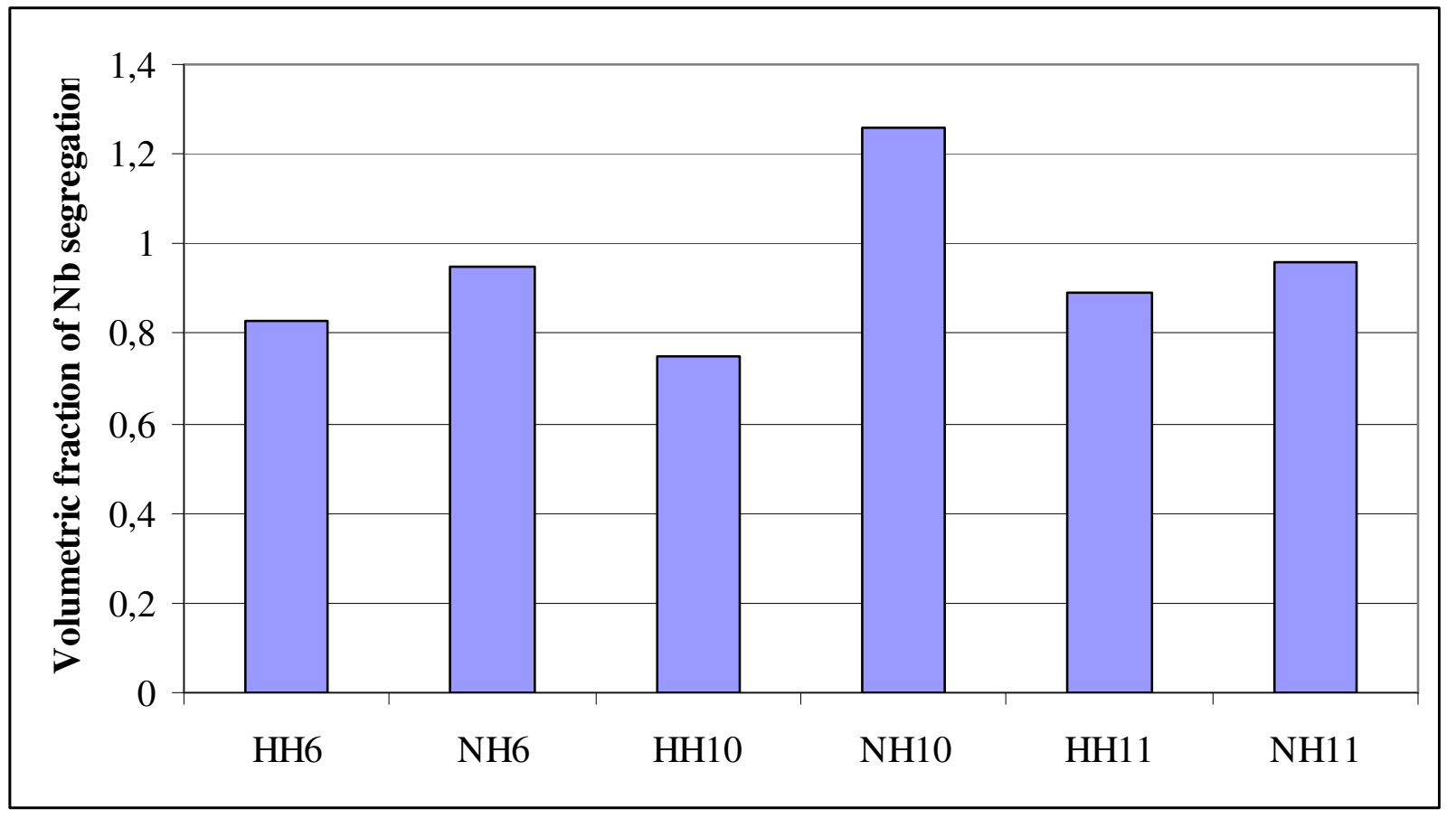

Figure 4. Volumetric fraction of $\mathrm{Nb}$ segregations in 718Plus cast samples after thermal treatments.

At the same time, the higher solution temperatures have also contributed to dissolve larger amounts of $\delta$ phase, making more $\mathrm{Nb}$ and other hardening elements available for forming hardening phases. This can be observed when comparing Micrographs 1 and 2 to Micrographs 3 and 4 , respectively. The $\delta$ phases formed around $\mathrm{Nb}$ segregations extend more into the matrix when the solution temperature is lower. At higher solution temperatures, those $\delta$ needles are dissolved and thus the $\mathrm{Nb}$ is free to form other hardening phases. 


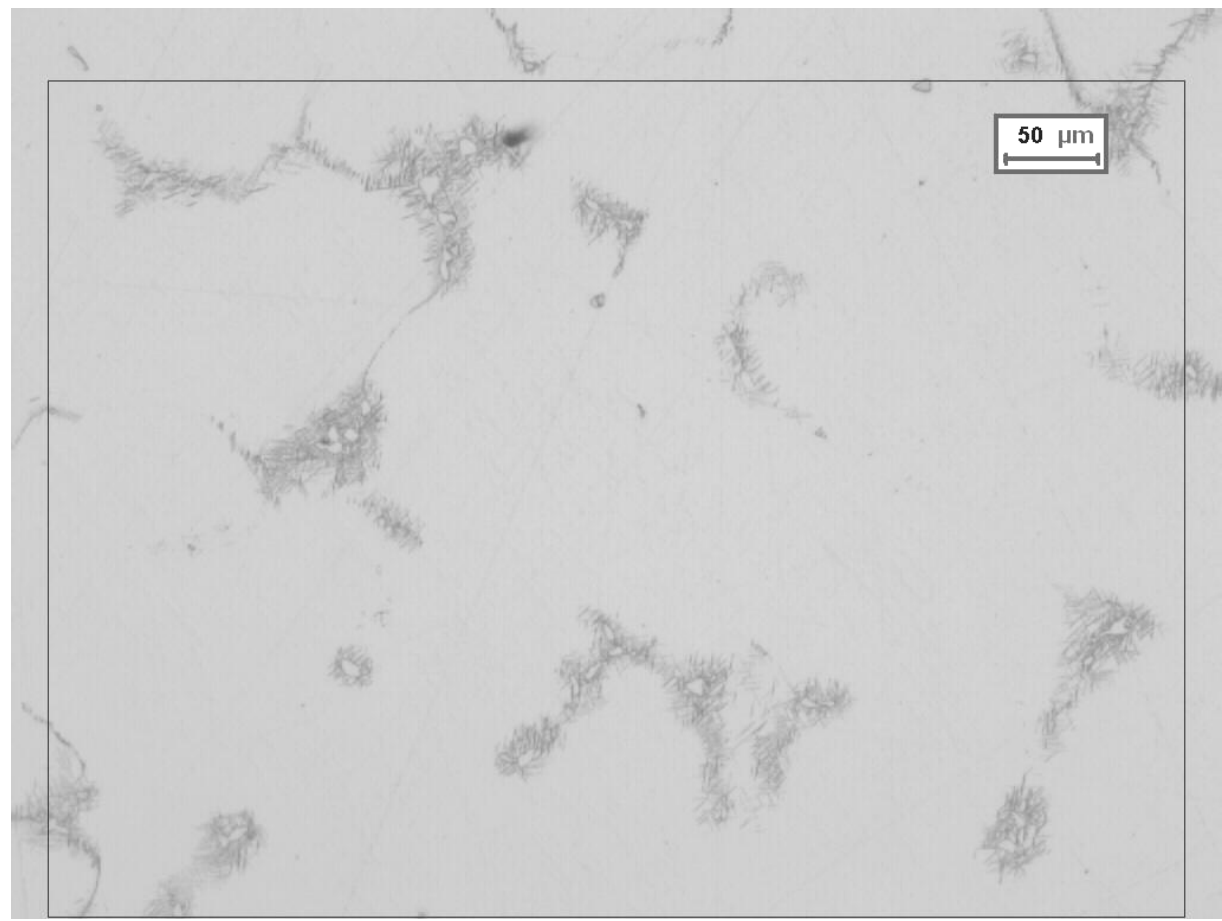

Micrograph 1: Metallographic sample $\mathrm{HH} 1$, solutioned at $954^{\circ} \mathrm{C}$ from Homogenized and HIPed ring.

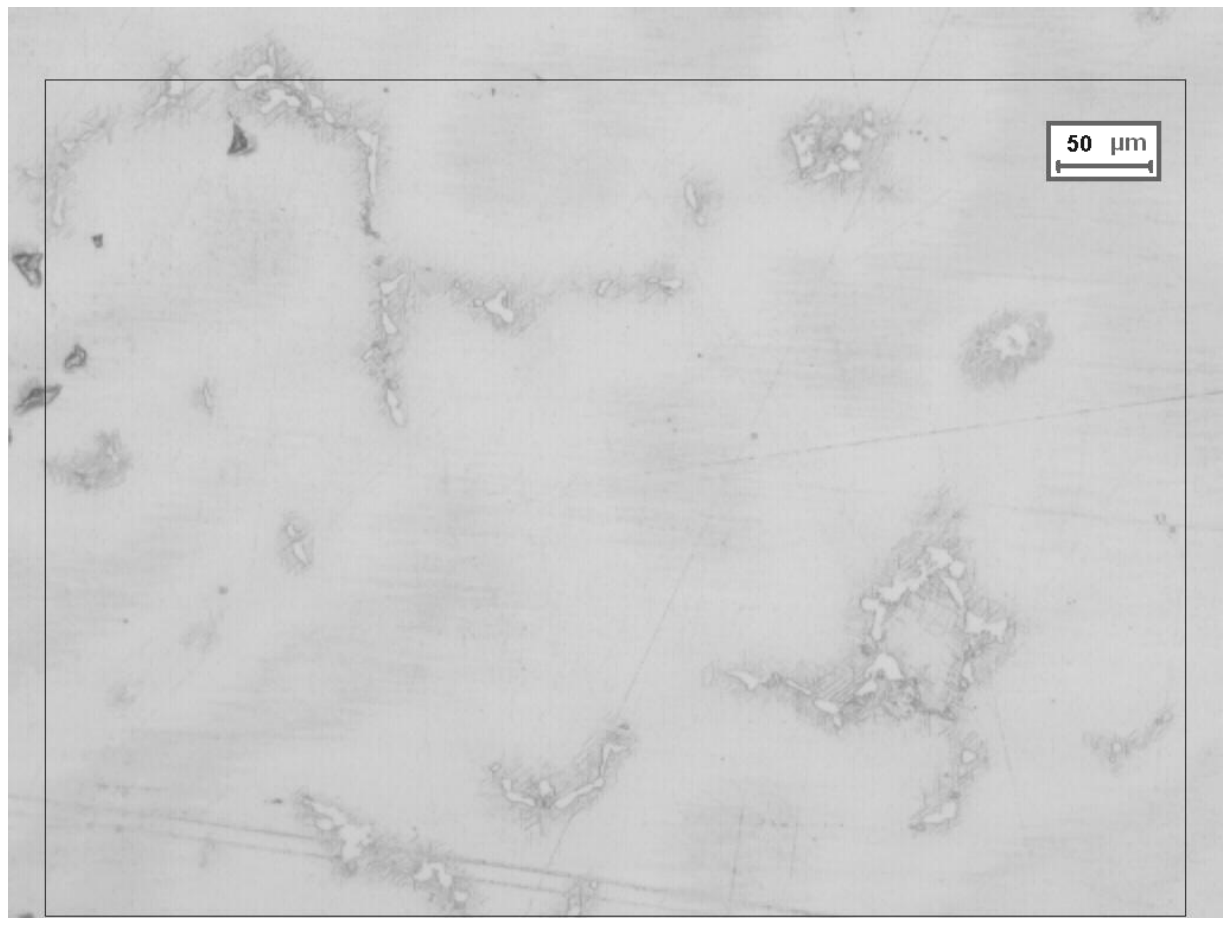

Micrograph 2: Metallographic sample NH1, solutioned at $954^{\circ} \mathrm{C}$ from only HIPed ring. Larger $\mathrm{Nb}$ segregations (than those in Micrograph 1) can be observed. 


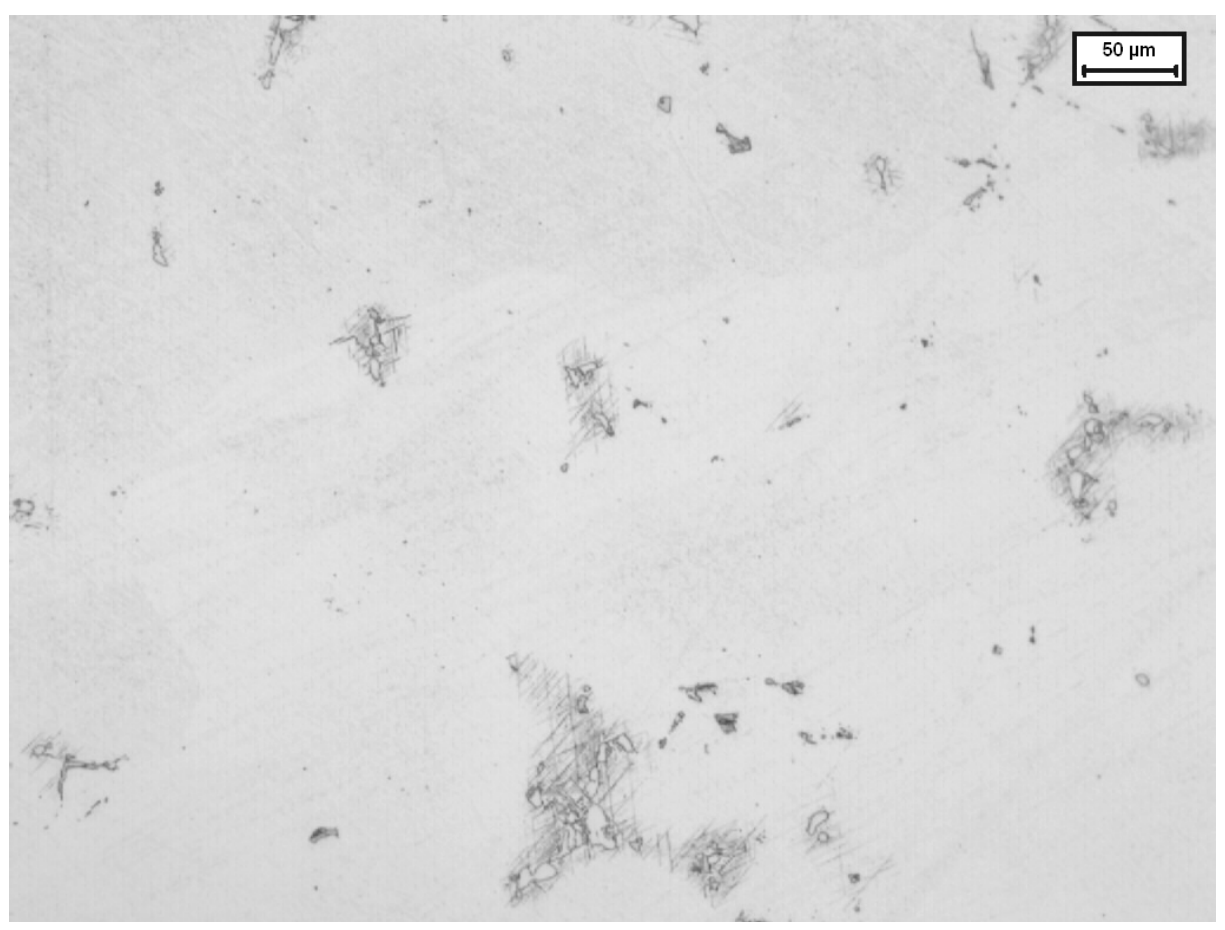

Micrograph 3: Metallographic sample HH5, solutioned at $1066^{\circ} \mathrm{C}$ from Homogenized and HIPed ring.

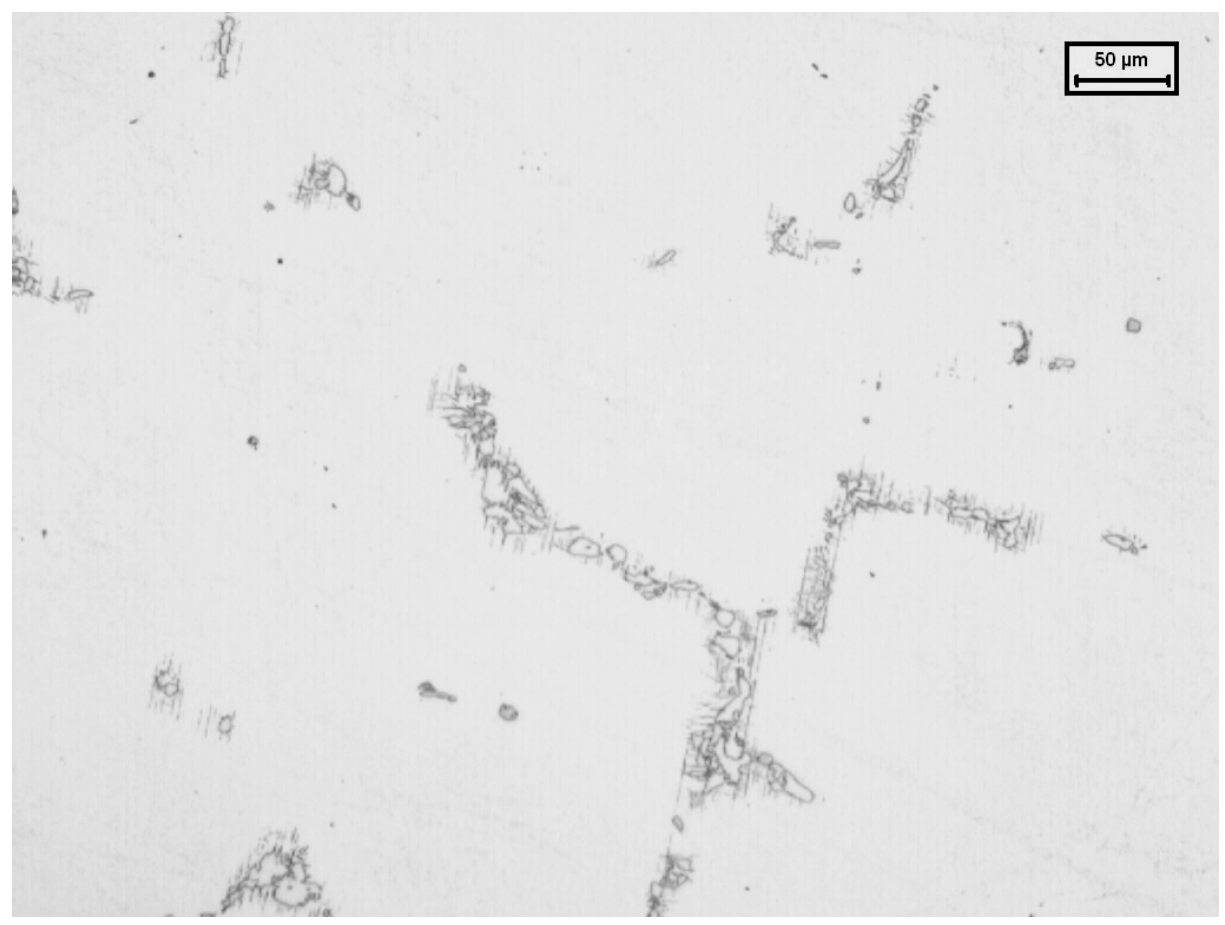

Micrograph 4: Metallographic sample NH5, solutioned at $1066^{\circ} \mathrm{C}$, from only HIPed ring.

The blocky islands found in these micrographs were assumed to be segregations formed during the solidification process of these rather thick rings, with $\mathrm{Nb}$ retained in them. This was confirmed later on through EDAX analysis in the SEM, see Micrograph 5 and Table 4. 


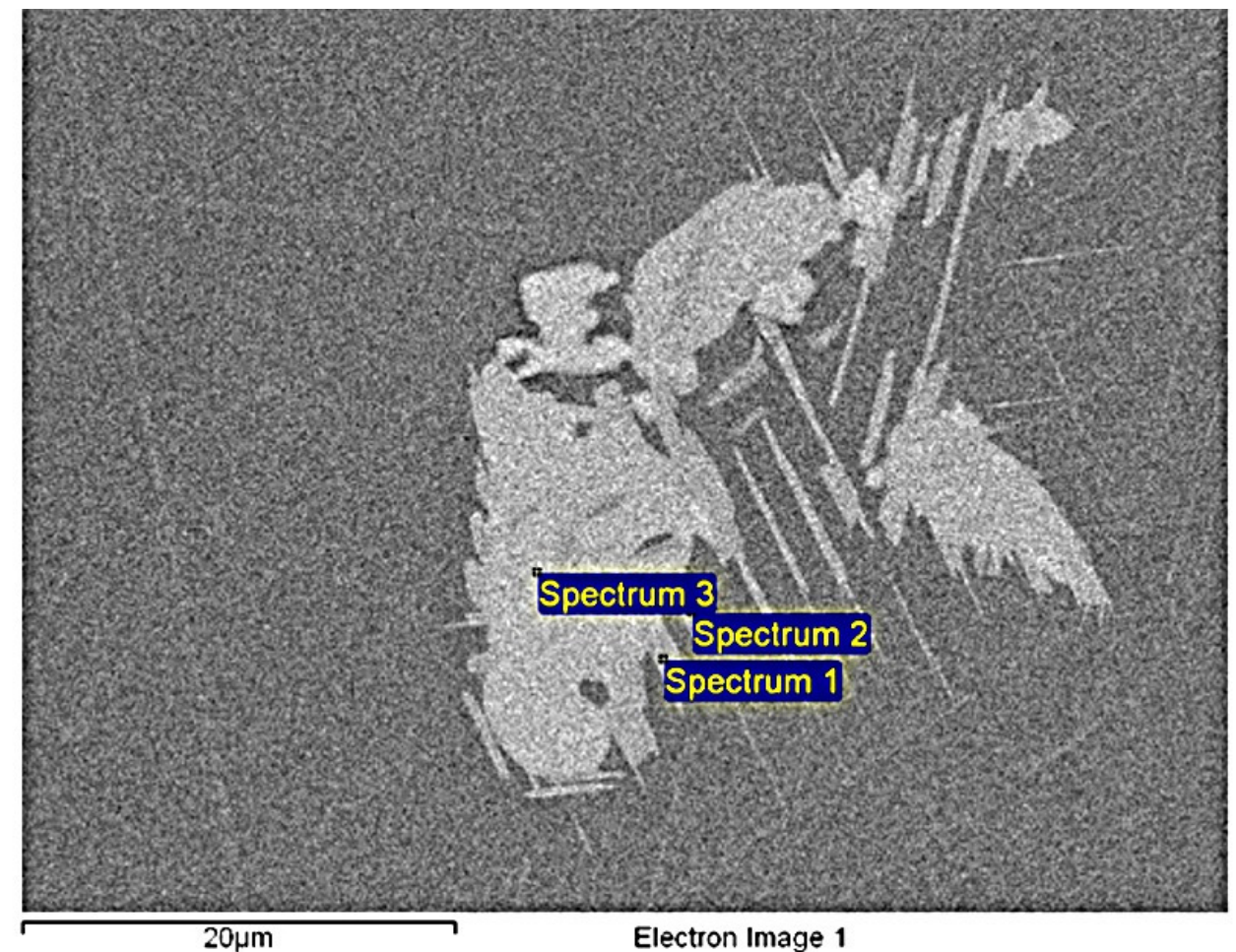

Micrograph 5: FEG-SEM (BSE) micrograph of NH5 sample (ST: $\left.1066{ }^{\circ} \mathrm{C}\right)$

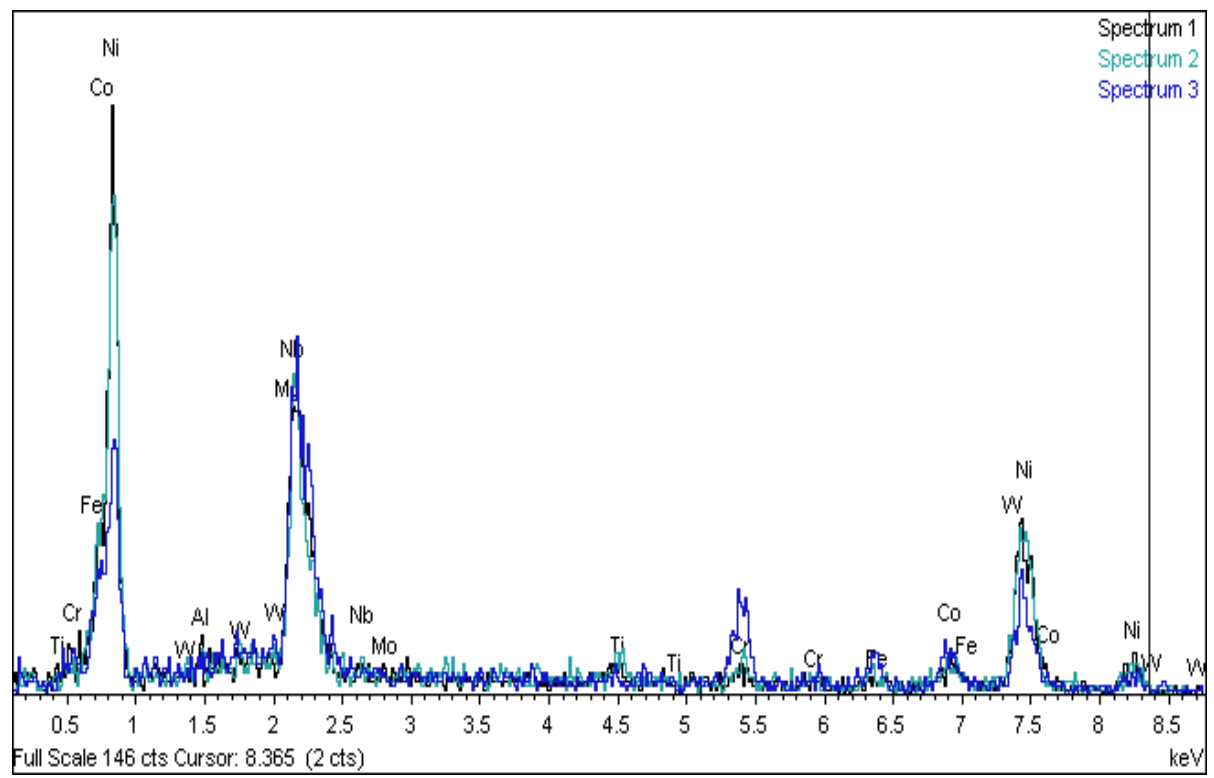

\begin{tabular}{|c|c|c|c|c|c|c|c|c|c|}
\hline Spectrum & Al & Ti & Cr & Fe & Co & Ni & Nb & Mo & W \\
\hline Spectrum 1 & 0.64 & 1.16 & 2.56 & 1.56 & 6.49 & 54.53 & 29.54 & 2.40 & 1.11 \\
\hline Spectrum 2 & 0.21 & 2.13 & 3.10 & 2.90 & 6.14 & 53.90 & 28.15 & 1.34 & 2.13 \\
\hline Spectrum 3 & 0.47 & 0.42 & 10.97 & 5.34 & 10.73 & 34.12 & 30.27 & 5.88 & 1.80 \\
\hline
\end{tabular}

Table 4: EDS micro-analyses of marked zones at Micrograph 5. 


\section{Discussion}

Clearly, on the $982^{\circ} \mathrm{C}$ and $1010^{\circ} \mathrm{C}$ solution micrographs, more precipitation of acicular $\delta$ phase is observed than in the $954^{\circ} \mathrm{C}$ solution micrographs (darker areas in micrographs). Comparison of Micrographs 6, 7 and 8 shows this effect. The blocky islands, whiter zones surrounded by the $\delta$ phase, were identified as $\mathrm{Nb}$ segregations, as explained earlier.

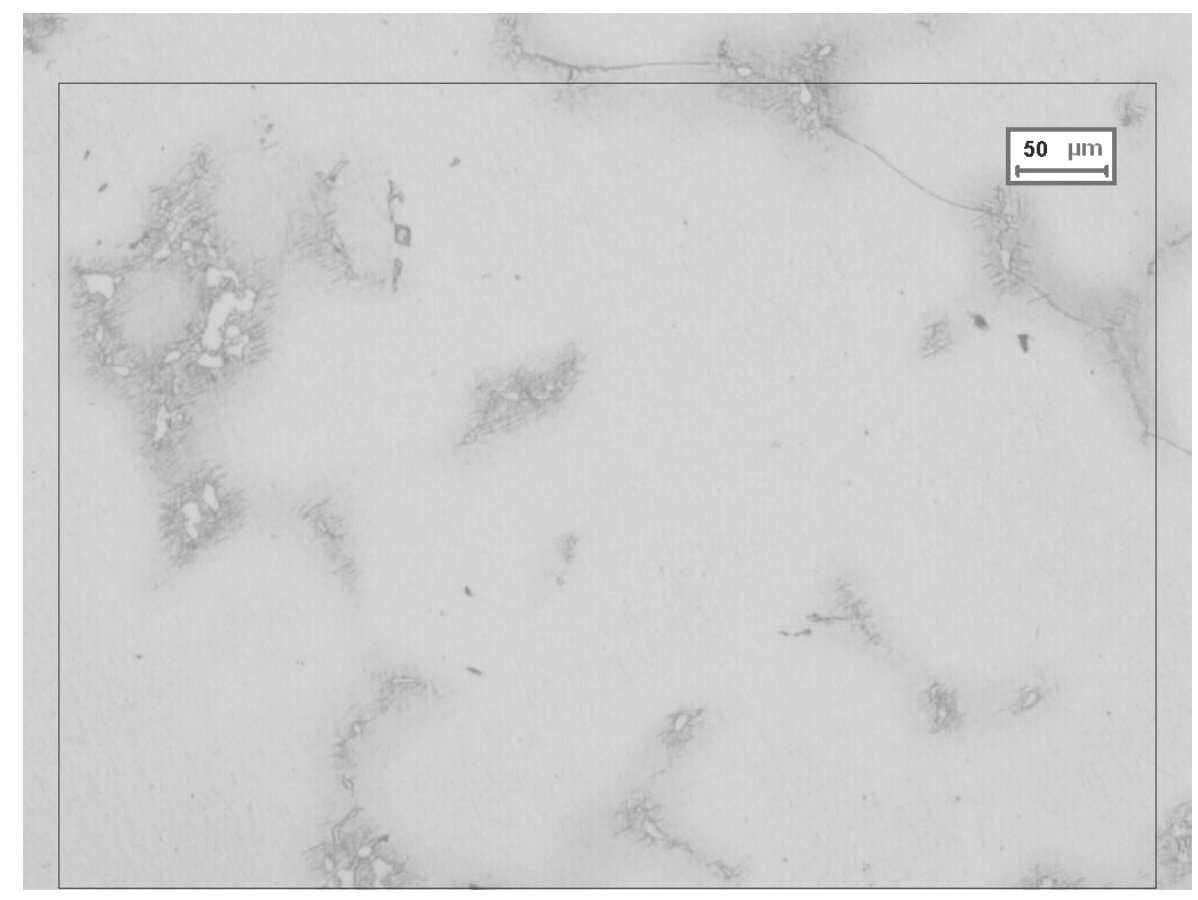

Micrograph 6 : Metallographic sample HH6, solutioned at $954^{\circ} \mathrm{C}$ and aged, from Homogenized and HIPed ring.

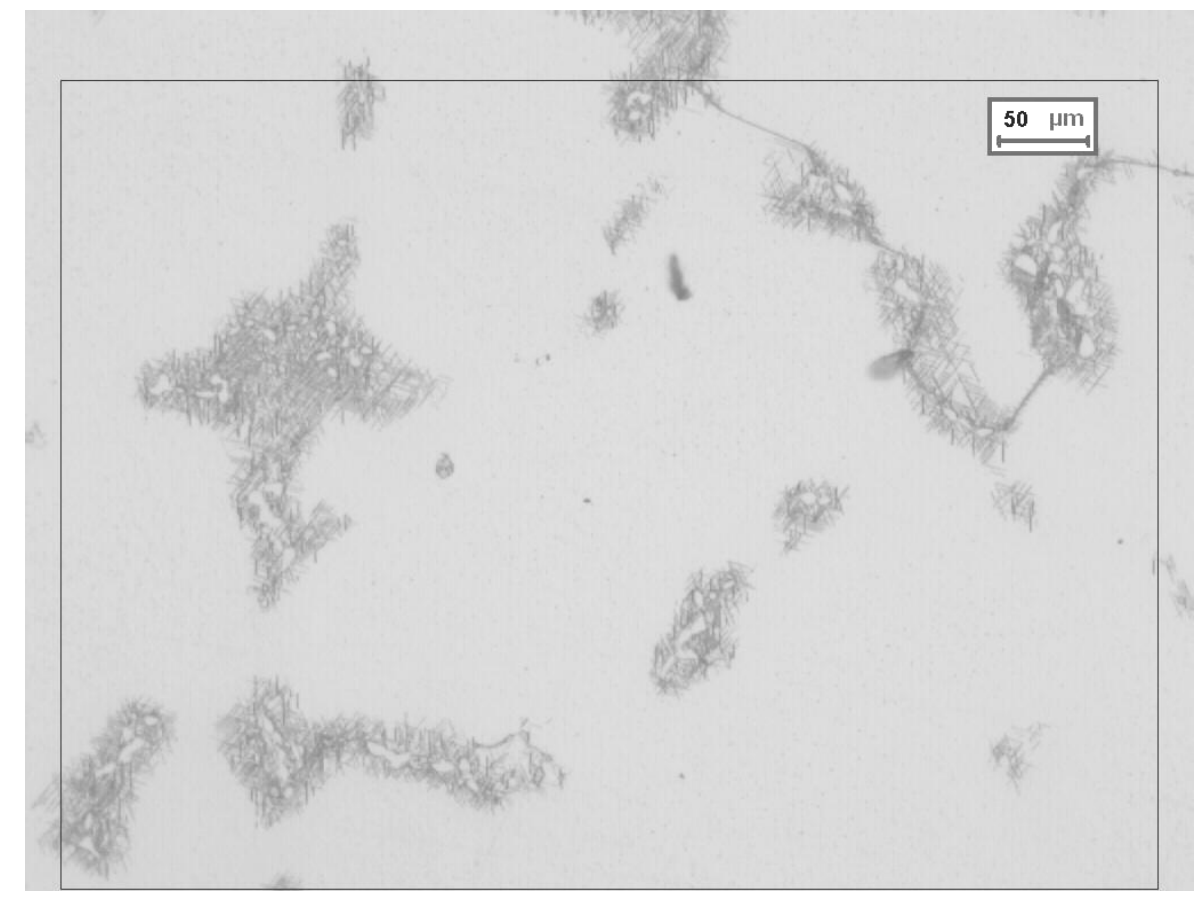

Micrograph 7: Metallographic sample HH7, solutioned at $982^{\circ} \mathrm{C}$ and aged, from Homogenized \& HIPed ring. 


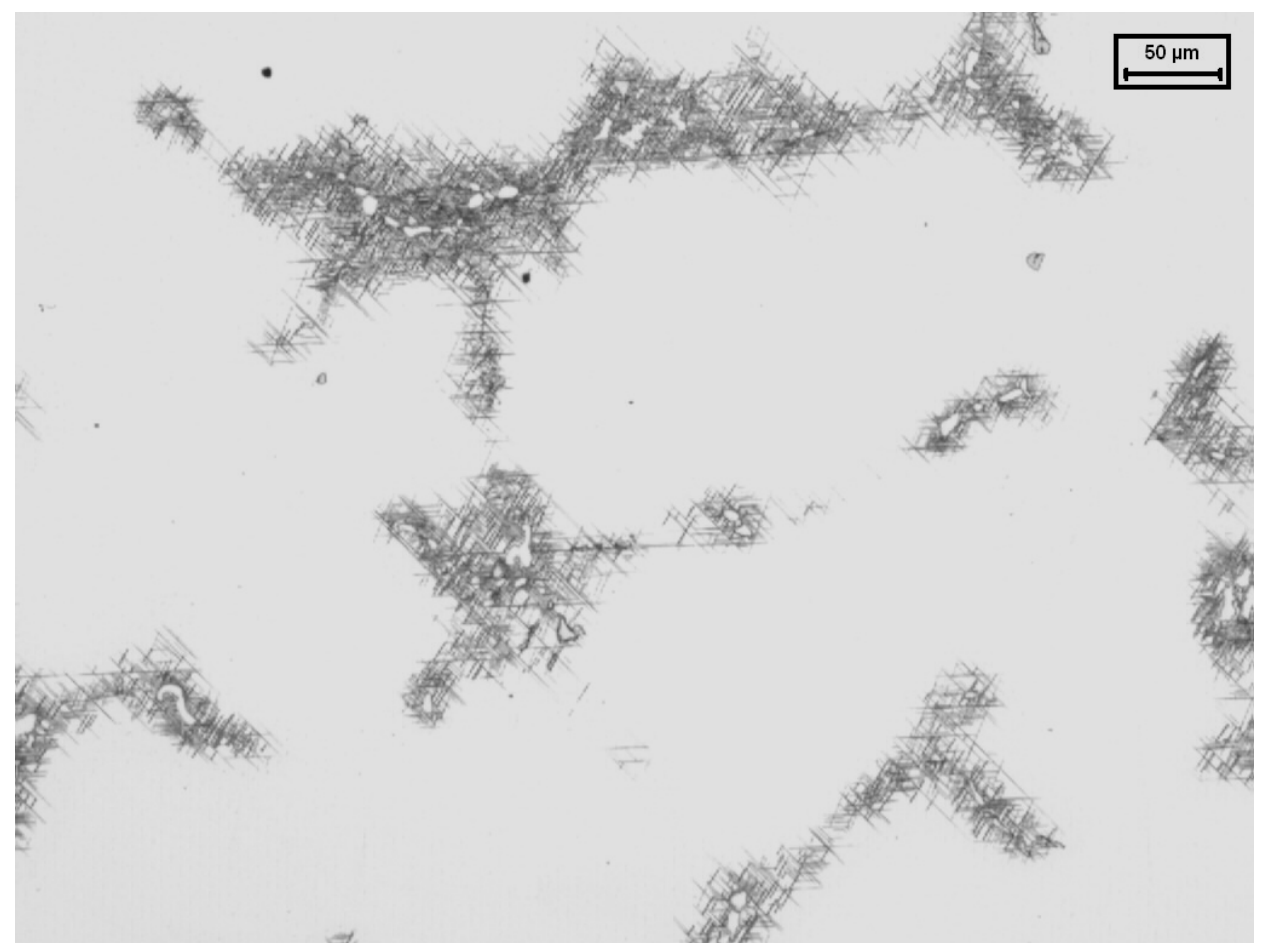

Micrograph 8: Metallographic sample $\mathrm{HH} 8$, solutioned at $1010^{\circ} \mathrm{C}$ and aged, from Homogenized \& HIPed ring.

However, it is surprising that $\delta$ phase is still present at $1038^{\circ} \mathrm{C}$ or $1066^{\circ} \mathrm{C}$. This $\delta$ phase should have been completely dissolved at these temperatures. See Micrographs 9 to 12.

It is thought that the $\delta$ phases are still present even after application of very high solution temperatures because they are surrounding the $\mathrm{Nb}$ segregation areas. For the same heat treatment condition, and throughout the different steps, $\delta$ phase seems to continue to form from the prior as-cast $\mathrm{Nb}$ segregation. As the $\mathrm{Nb}$ dissolves during heat treatment, there is more $\mathrm{Nb}$ available to form $\delta$ phase. Thus, both the volume fraction and size of acicular $\delta$ phase increases as heat treatment progresses through its steps.

The volume fraction and size of acicular delta phase and $\mathrm{Nb}$ seggregated areas are also observed to depend on what solution temperature is applied. $\delta$ phase volume fraction seems to be maximum when the solution temperature is $982^{\circ} \mathrm{C}$, but decreases again with higher solution temperatures. $\delta$ phase starts to solve when the temperature is above $1000^{\circ} \mathrm{C}$, which is known to be the range of $\delta$ solvus.

As there is always a transition area between the $\mathrm{Nb}$ segregation and the matrix, the $\delta$ still appears there, but the higher solution temperatures cause these $\delta$ phase needles to get into solution quicker when they pass through these temperatures, making more hardening elements available to form precipitates, which are not visible in the optical microscope. This reasoning is consistent with hardness values measured in the exposed condition. 


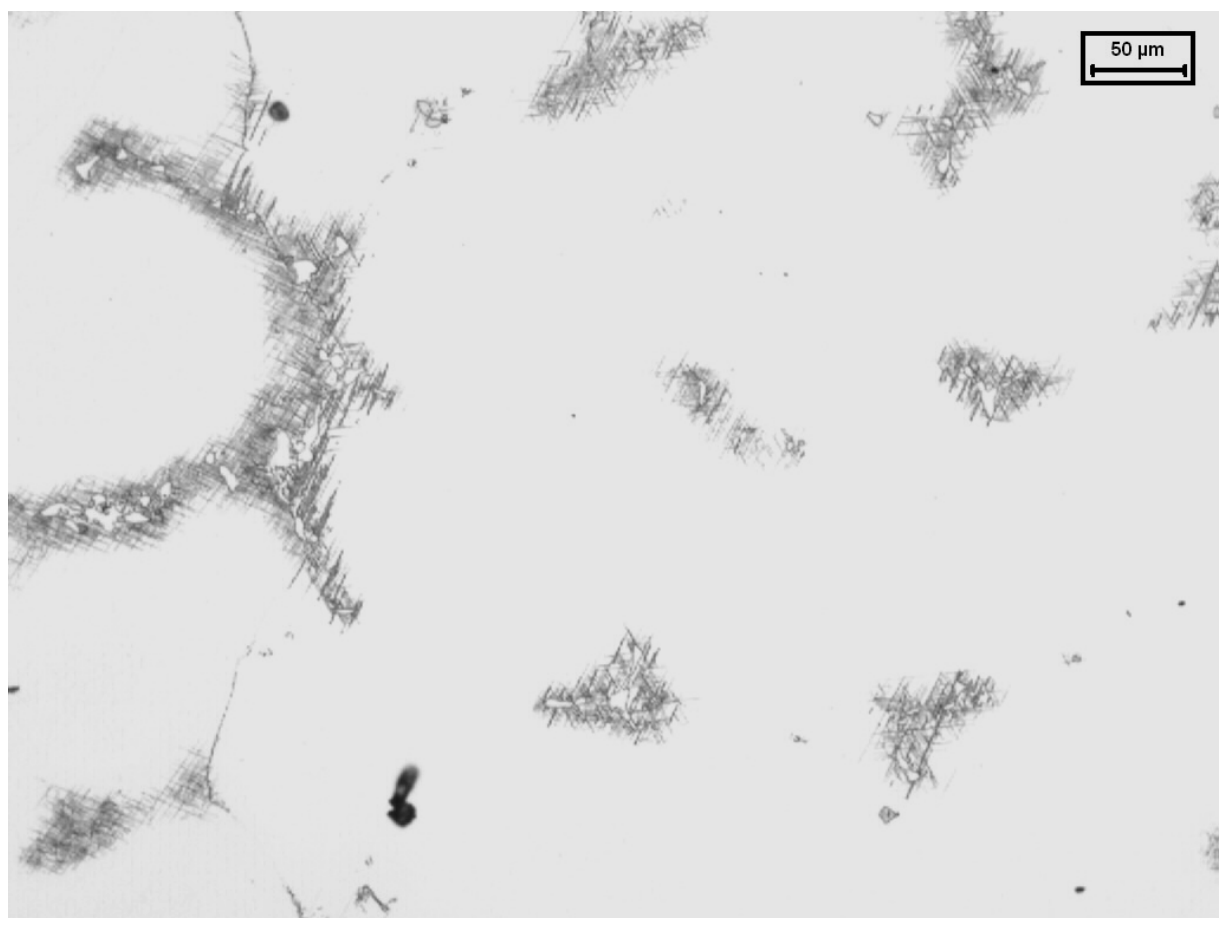

Micrograph 9: Metallographic sample $\mathrm{HH} 9$, solutioned at $1038^{\circ} \mathrm{C}$ and aged, from Homogenized \& HIPed ring.

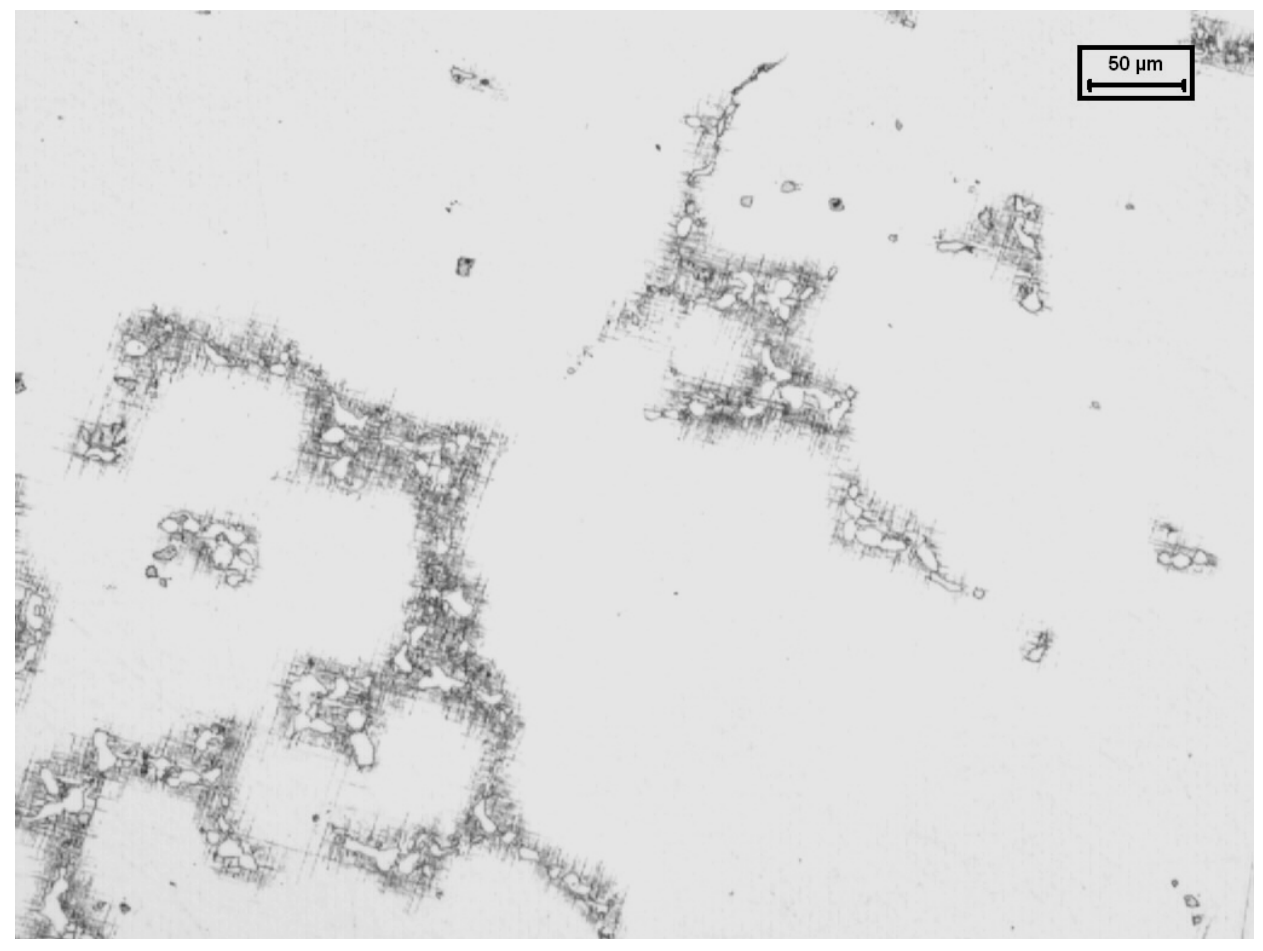

Micrograph 10: Metallographic sample HH10, solutioned at $1066^{\circ} \mathrm{C}$ and aged, from Homogenized \& HIPed ring. 


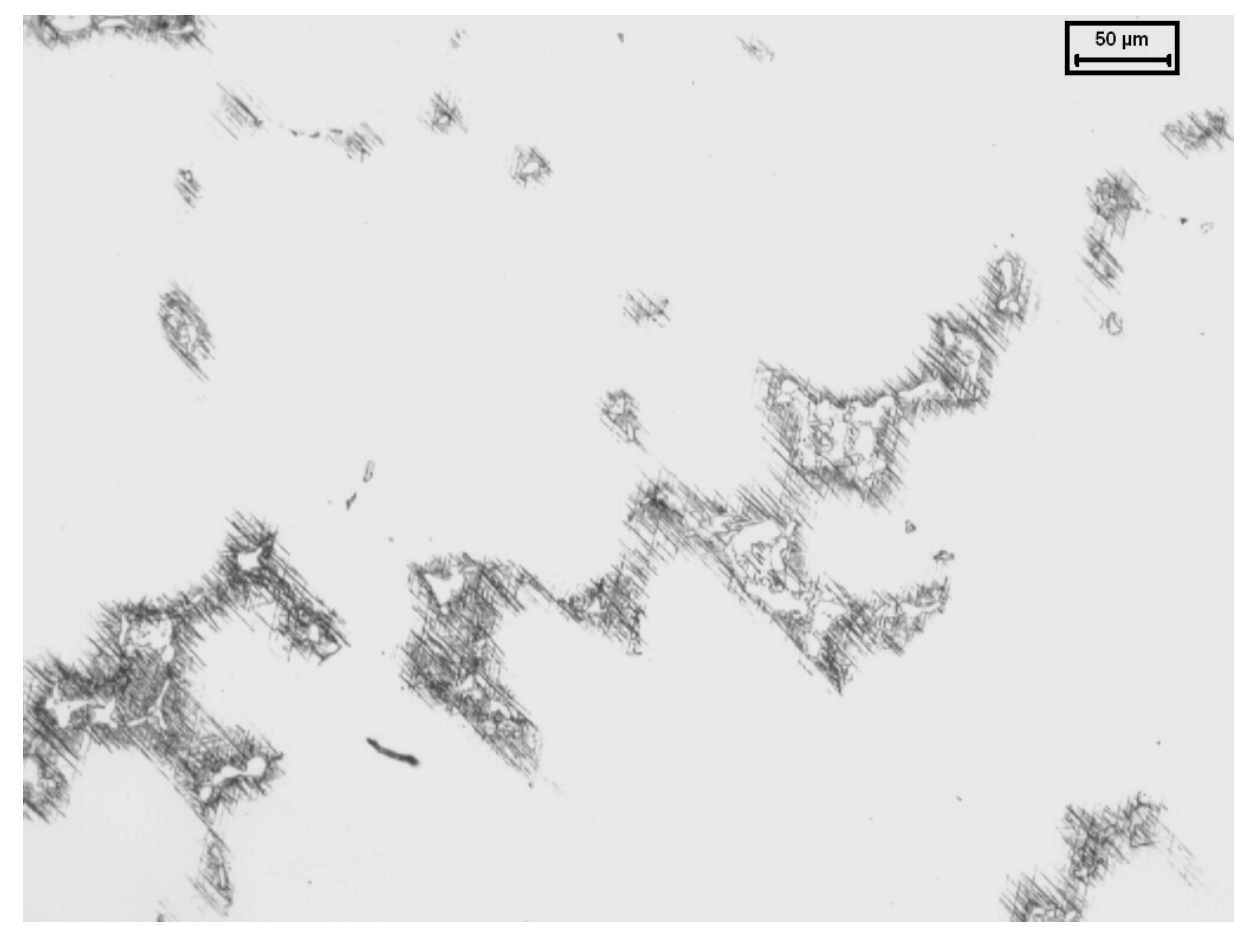

Micrograph 11: Metallographic sample NH9, solutioned at $1038^{\circ} \mathrm{C}$ and aged, from only HIPed ring.

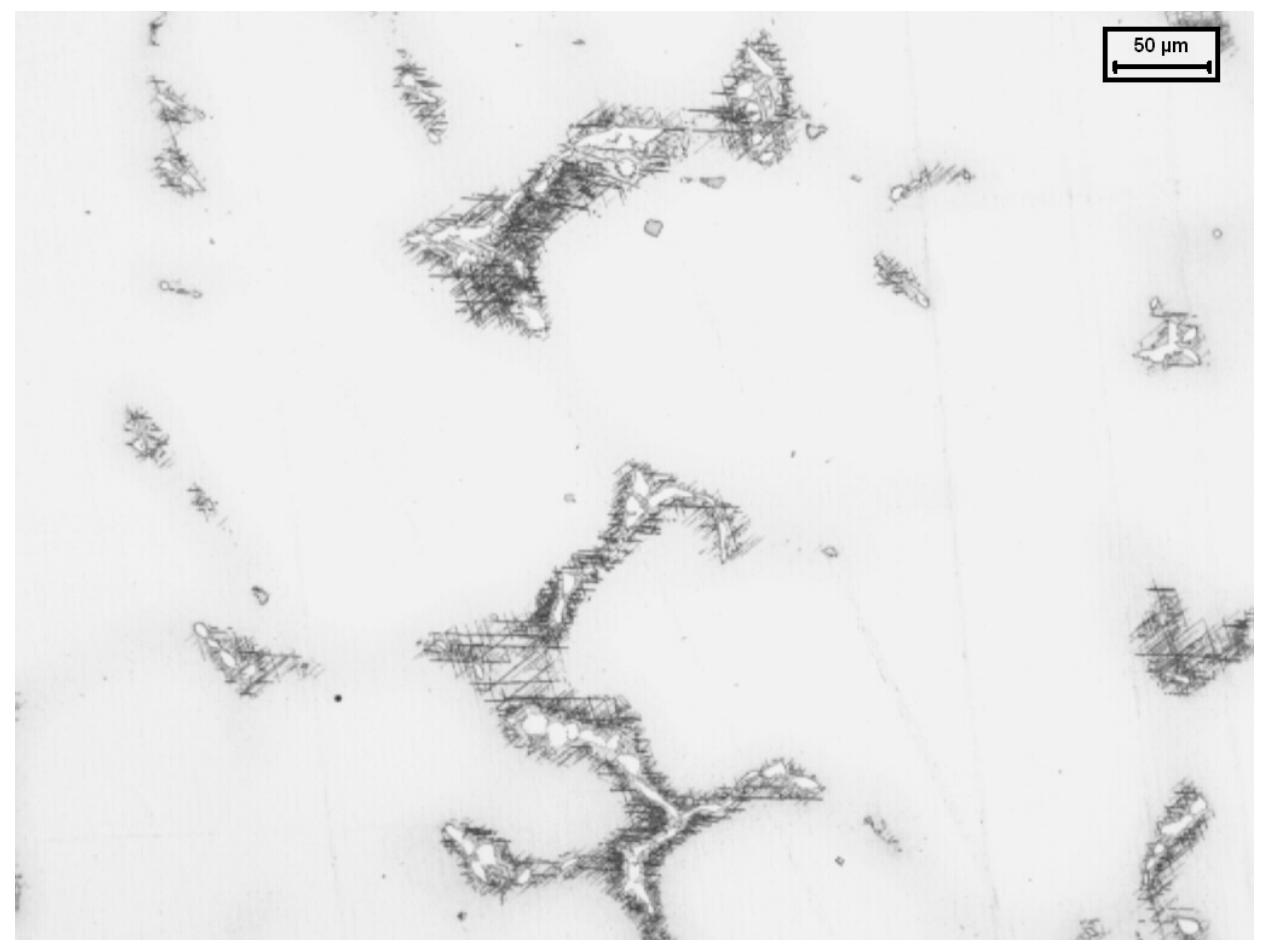

Micrograph 12: Metallographic sample NH10, solutioned at $1066^{\circ} \mathrm{C}$ and aged, from only HIPed ring. 
In order to assess the effect of thermal exposure on the material, $\gamma$ 'phase sizes were also measured. Table 5 shows some of these sizes to illustrate the growth of these precipitates. This particular case shows that the growth of $\gamma$ 'phase is related with a decrease in the hardness values, but this is almost the only case in which this happens. A possible rationale for the increase of the hardness values at the rest of the solution temperatures is that these higher solution temperatures achieved an effective solution of $\delta$, making more $\mathrm{Nb}$ available to form other hardening phases, such as $\gamma^{\prime}$ ', and this was the one responsible for the increase in hardness values. However, it is difficult to admit this, as the alloy is known to be primarily hardened by $\gamma^{\prime}$, and not by $\gamma^{\prime}$ '.

\begin{tabular}{|c|c|c|}
\hline Sample & Average diameter or length of $\boldsymbol{\gamma}^{\prime}(\mathbf{n m})$ & Standard deviation $(\mathbf{n m})$ \\
\hline NH6 & 110 & 10 \\
\hline HH11 & 140 & 20 \\
\hline NH11 & 140 & 10 \\
\hline
\end{tabular}

Table 5. Average size and standard deviation of $\gamma^{\prime}$ precipitates, for the different samples.

It is also observed that the sizes of the precipitates do not change regardless the previous application or not of homogenzation heat treatment. This indicates that homogenisation only dissolves segregations to make more hardening elements available, but doesn't really have any effect on the size or morphology of precipitates formed later in the heat treatment.

Finally, after all observations, $982^{\circ} \mathrm{C}$ was selected as the solution temperature, which is at the upper end of the wrought material AMS specification range for solution heat treatment.The volume fraction of acicular $\delta$ phase is also higher than with the $954^{\circ} \mathrm{C}$ solution temperature, which is at the lower end of the same AMS specification. The hardness values, which give an indication of mechanical properties of the material condition, are higher than those obtained with the $954^{\circ} \mathrm{C}$ solution heat treatment.

Although the application of homogenization demonstrated a better distribution of hardening elements, the benefit was not judged to a significant improvement. As no deleterious effect was observed when homogenization was not employed, and bearing in mind the cost reduction associated to removal of this treatment, it was decided to only HIP the cast material.

Therefore, the remainder of the ring that had not received the homogenization heat treatment was selected for mechanical properties characterization, and the $982^{\circ} \mathrm{C}$ solution heat treatment was applied to this material. Results on these tests are detailed elsewhere [5].

\section{Conclusions}

1. The $982^{\circ} \mathrm{C}$ and $1010^{\circ} \mathrm{C}$ solution treatments produced more precipitation of acicular $\delta$ phase than the $954^{\circ} \mathrm{C}$ solutioning. Formation of $\delta$ phase is promoted at these higher temperatures, as diffusion of $\mathrm{Nb}$ occurs from the as-cast $\mathrm{Nb}$ rich segregation areas.

2. Some $\delta$ phase is still present after $1038^{\circ} \mathrm{C}, 1066^{\circ} \mathrm{C}$ solution treatments. This $\delta$ should have been completely dissolved under equilibrium conditions at these temperatures. It is thought that it is still present because it is formed from the $\mathrm{Nb}$ segregation areas, as there is always a transition area between the $\mathrm{Nb}$ segregation and the matrix. In other words, precipitation of $\delta$ phase is usually produced by overaging, but it also happens because of the diffusion of the $\mathrm{Nb}$ segregations during solution heat treatment. 
3. On the only HIPed metallographic samples, the $\mathrm{Nb}$ segregations are bigger or present in higher quantity; percentage of present phase and phase-sizes are higher. The homogenization heat treatment worked out satisfactorily in spite of being $1 \mathrm{hr}$ and $1095^{\circ} \mathrm{C}$, that is shorter and at lower temperature that the HIP.

4. Clear over-aging of samples solutioned at lower temperatures, has happened because of the thermal exposition treatment. This point has been observed not only by FEG-SEM images and measurements of the $\gamma$ ' size that reveals its coarsening, but also by hardness measurements. Higher solution temperatures change the sense of this effect. This could be attributed to the formation of additional $\gamma$ " from $\mathrm{Nb}$ stemming from dissolution of segregations.

5. Previous homogenization treatment does not affect the size of $\gamma^{\prime}$ precipitates.

\section{References}

1. “Allvac® 718Plus ${ }^{\circledR}$, Superalloy for the Next Forty Years”, R.L. Kennedy, Superalloys 718, 625, 706 and Various Derivatives, TMS, 2005.

2. "Role of Chemistry in 718-Type Alloys - Allvac® 718Plus® Alloy Development", W.D. Cao, R. Kennedy, Superalloys 2004.

3. "Developments in Wrought Nb Containing Superalloys $\left(718+100{ }^{\circ} \mathrm{F}\right)$ ”, R.L. Kennedy, W.D. Cao, T.D. Bayha, R. Jeniski, TMS, 2003.

4. "Comparison between the Microstructure and the Mechanical Properties of In718 and 718Plus Alloys after Exposition” T. Gómez-Acebo, A.J. Lopez, J.C. Rodríguez, O. Caballero, M. Goiricelaya, K. Celaya, G. Sjoberg, M. Hörnqvist, Superalloy 718 symposium, Pittsburgh, October 2010.

5. "Overview on 718Plus assessment within VITAL project”, O. Caballero; G. Sjoberg; T. Gómez-Acebo, Superalloy 718 symposium, Pittsburgh, October 2010. 